\title{
The Influence of Family Background on Urban and Rural Laborers' Employment Opportunities
}

\author{
Gao Ran1, a \\ ${ }^{1}$ Shangda road no.99 in Shanghai baoshan district \\ a1907756912@qq.com
}

Keywords: Urban and rural workers, Employment opportunities, Family background, Probit model

\begin{abstract}
This paper focuses on the perspective of urban and rural employment opportunities and the urban-rural wage inequality caused by family background according to the statistics of Henan Province in 2014. According to the calculation, the factors that urban residents and their fathers engaging in high-wage industries have a significant positive impact on their employment opportunities, and higher education can narrow the income gap between urban and rural workers.
\end{abstract}

\section{Introduction}

As increasing people talk about the idea of the uselessness of study, we start to think about the rate of return to education. Education is important for people to obtain human capital and the rate of return to education directly affects people's human capital investment. Some existing researches show that the rate of return to education in rural area is far lower than that in towns. Sun Zhijun (2004) said that the rate of return to education of Chinese workers in cities was nearly 2 times as much as that of rural workers. How should we consider this problem? (Ye Guang, 2015)Zheng Maoxiong (2012), Zheng Jie (2004) and Kang Xiaoming (2006) and other scholars studied the relations among family social capital, graduates' employment statue and their working satisfaction. Wen Dongmao (2005), Wang Bing (2008) and others used family background as the quantitative criteria of social capital to analysis its impact on opportunities of higher education and the graduate employment in China.

\section{The Data Resources and Statistical Description}

In this paper, the data is based on 1157 questionnaires from a questionnaire survey that our research team made in Henan Province during the 2014 summer practice. Some parts of the questionnaire variables are missing, which have to be excluded, the subjects investigated are limited to the 16-60 year old workers, and we have to control the influence of unequal educational opportunities, we select college or above students as samples. Finally, the paper chooses 423 samples to analysis the influence of family background on rural and urban residents who work in towns.

Inaccordance with the International and Chinese Standard Industrial Classification of Industry,the survey involves a total of 21 sectors: government, finance, insurance, IT, electronics, real estate, automobiles, house hold appliances, medical care, education, transportation, individual, manufacturing, freelance, consulting, investment, trade, building materials, tourism, wholesale and retail, restaurants, farming. According to "China Statistical Yearbook", it shows that the government, 
finance and insurance, IT, real estate, automotive, medical, investment, and trade are regarded as the high-wage industries, and another 13 industries are regarded as the low-wage industries. Table 1 shows the proportion of urban and rural workers in these high-wage industries.

Table 1 Employment Distribution of Urban and Rural Workers in High-wage Industrie

\begin{tabular}{c|ccccc}
\hline \multirow{2}{*}{ Industry } & \multicolumn{2}{c}{ the Number of Samples } & \multicolumn{2}{c}{ Proportion(\%) } & $\begin{array}{c}\text { Average } \\
\text { Wage(Yuan) }\end{array}$ \\
\cline { 2 - 5 } Government Office & Urban & Rural & Urban & Rural & 3143.92 \\
Finance and & 68 & 17 & 80.00 & 20.00 & 6213.95 \\
IT & 36 & 7 & 83.72 & 16.28 & 5868.18 \\
Real Estate & 17 & 5 & 72.27 & 22.72 & 5150.00 \\
Automotive & 9 & 3 & 75.00 & 25.00 & 5240.00 \\
Medical Care & 5 & 0 & 100 & 0 & 3825.00 \\
Investment & 13 & 3 & 81.25 & 18.75 & 5318.18 \\
Trade & 10 & 1 & 90.90 & 9.10 & 5752.50 \\
\hline Total & 3 & 1 & 75.00 & 25.00 & 5063.84 \\
\hline
\end{tabular}

To further investigate the position differences between urban and rural workers, the results are as shown in Table 2:

Table 2 the Distribution of Urban and Rural Workers in Management Level and Basic Level

\begin{tabular}{|l|l|l|l|l|l|l|}
\hline & \multicolumn{2}{|l|}{ the Number of Samples } & \multicolumn{2}{l|}{ Proportion } & \multicolumn{2}{l|}{ Average Wage } \\
& Urban & Rural & Urban & Rural & Urban & Rural \\
\hline Management & 133 & 34 & 42.36 & 33.01 & 4826.99 & 3847.06 \\
\hline Basic Level & 181 & 69 & 57.64 & 66.99 & 3569.06 & 2908.48 \\
\hline Total & 314 & 103 & 100 & 100 & 8396.05 & 6755.54 \\
\hline
\end{tabular}

The proportion of urban workers in management positions is 9.3\% higher than that of rural workers. Furthermore, even if they are in the same positions, the average wage of urban managers is 35\% higher than that of rural ones, the average wage of primary-level urban workers $32 \%$ higher than that of rural workers in the same positions. These differences cannot be all ascribed to the diversities of personal factors of workers and labor capacity.

\section{Model Specification and Estimation Methods}

(A) Selecting Variables 
Table 3 Variable Description

\begin{tabular}{|c|l|}
\hline $\begin{array}{c}\text { Individual } \\
\text { Characteristics }\end{array}$ & $\begin{array}{l}\text { Length of Education(edu) } \\
\text { Working Experience(exp) } \\
\text { Gender(Male: male=1; Female: } \text { male=0) }\end{array}$ \\
\hline Family & $\begin{array}{l}\text { Parental Household Registration(urban: } \text { urban=1; rural: urban=0) } \\
\text { Maximum Schooling Years of Parents, (hedu) } \\
\text { Whether fathers work in high-wage industry (Yes; fhighind=1; No: fhighind=0) }\end{array}$ \\
\hline Employment & $\begin{array}{l}\text { Industry Situation of Respondents (working high-paid industry: highind=1; working in } \\
\text { low-paid industry: highind=0) } \\
\text { Position Grade of Respondents (Management Level:manage=1; Basic Level: } \text { manage=0) }\end{array}$ \\
\hline
\end{tabular}

(B) Model Specification

We utilize probitmodel and measure the employment opportunities of urban and rural worker through the distribution of high- and low- wage industries and positions in management and basic levels.

In accordance with the analysis of those data, we set a model to verify our point. Therein, weintroduce the workers' employment opportunities after controlling the influence of education and then explore how social relations affect the employment opportunities. Therefore, we establish the following latent variable model:

$$
\begin{aligned}
y= & \beta_{0}+\beta_{1} e d u+\beta_{2} \exp +\beta_{3} \exp ^{2}+\beta_{4} \text { hedu } * \text { urban } \\
& +\beta_{5} \text { fhiguind }{ }^{*} \text { urban }+\beta_{6} \text { hedu }+\beta_{7} \text { fhighind }+\beta_{8} \text { male }+\beta_{9} \text { urban }+u
\end{aligned}
$$

$y$ is the unobservable laten variable; edurepresents the schooling years; expmeans the working experience; hedu is the highest education of parents; fhighindis a dummy variable, representing that fathers work in high-wage industries; heduandfhighindare the indexes to measure family background; urban is the dummy variable at urban and rural household registration, and male is the dummy variable at gender. Introducing cross-product terms, hedu*urban and fhighind*urban, is to reflect the impacts of family background on employment opportunities of urban and rural employees and their positions.

According to the division of high-paid industries in Table 1, regard highindas the dummy variable at high-paid industries.If employees work in high-paid industries, highind=1; otherwise, highind $=0$. We establish the probit model as follows:

$$
\mathrm{P}(\text { highind }=1 \mid \Omega)=\Phi(y) \quad \text { (Model 1) }
$$

$\Omega$ denotes the information set of all the explanatory variables in the latent variable model,and $\Phi$ is the standard cumulative normal distribution function. We adopt the same method to study the influence of workers' individual characteristics and family social relations on position promotion and make managethe dummy variable at the job level,managementlevel manage $=1$ and others $=0$. The corresponding probitmodel is following:

$$
\mathrm{P}(\text { manage }=1 \mid \Omega)=\Phi(y)
$$

\section{Comparison and Analysis of the Empitical Results}

We evaluate the probit models of high-paid industries and position promotion respectively in Model 1 and Model 2 based on the data, the results as follows: 
Table 4 Evaluations of Employment Opportunities on Probit Model

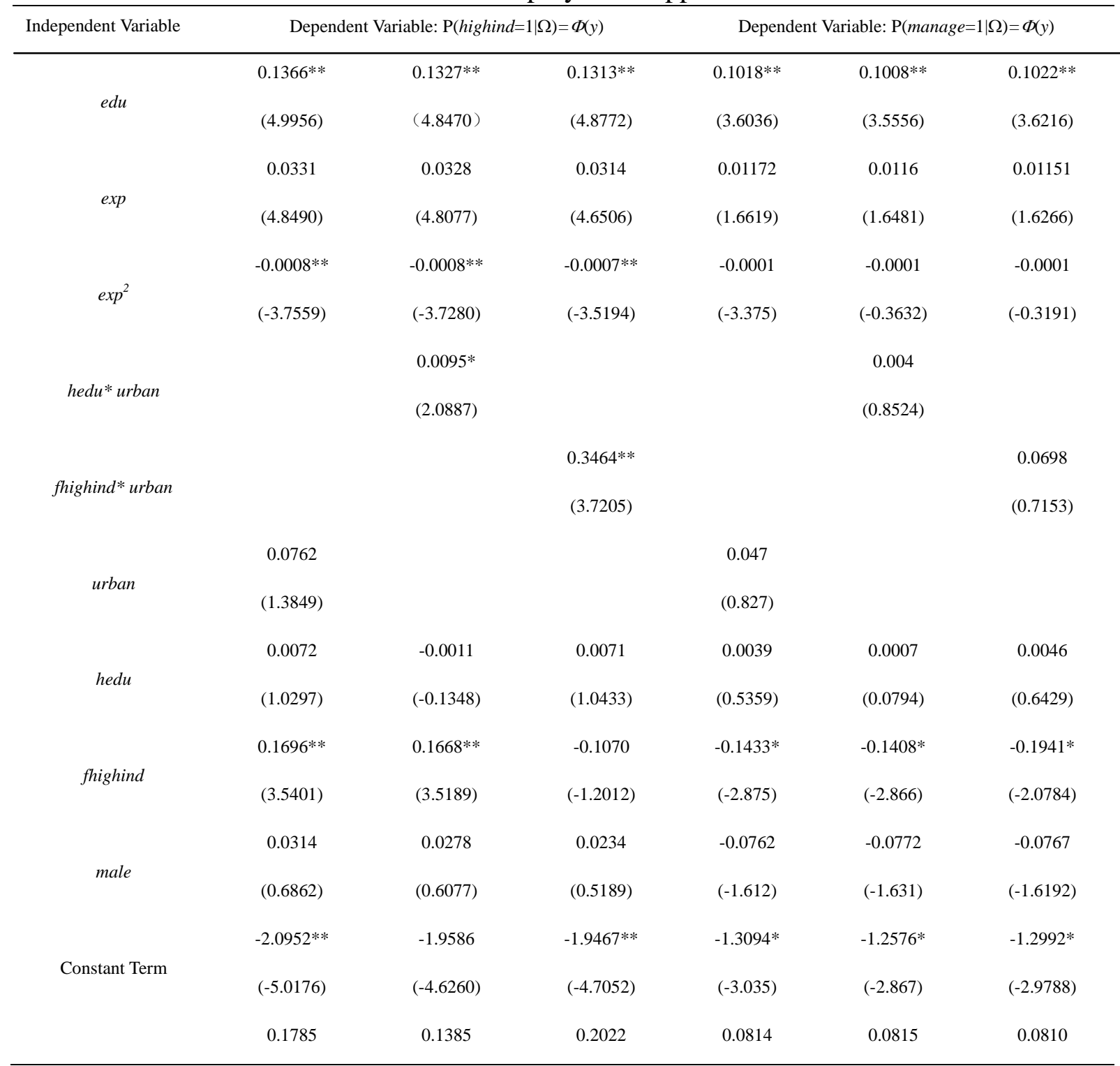

Note:t statistic value is in parentheses; ${ }^{* *}$ and * mean that it is obvious in the significance level of $1 \%$ and $5 \%$ respectively.

In the policy, we should perfect the labor market mechanism and try our best to eliminate inequality in employment opportunities caused by different family background to improve rural drop-out phenomenon and prevent the spread of "the uselessness of studying". Only that rural workers have the same employment opportunities as urban workers have when both of them are at the same educational level may eliminate the differences of urban and rural educational return and ensure rural workers will be more positive to study further. As urban and rural workers are better educated, the income gap between urban and rural workers and their position diversities will shrink. When urban-rurla education reaches to the master level, the advantage of urban background will be weak, and the wage of rural workers who work in cities and towns may even exceed that of urban workers.

\section{References}

[1] Ye Guang. Unequal Employment Opportunities, Low Return on Education and Urban-rural Income Income Gap[J].Economic Survey, 2015(4):25-30. 
[2] Wu Yuxiao. Educational Diversion System and Educational Stratification in China （1978-2008） [J].Sociological Study, 2013 (4).

[3] Zheng Maoxiong.Research on the Relation Between Family Social Capital and Employment Sstisfaction of Undergraduates[J].Higher Education Exploration, 2012 (12).

[4] Xu Xianghua,Chen Xuejuan.Empirical Research on the Effect of the Household Registration System Evolvement on Labor Market Segmentation in China: From Dual Perspectives of Employment Opportunities and Wage Gap [J].Economic Research Journal,2012(12).

[4] Li Jun, Gu Yanfeng. 2011. Household Registration Segmentation on Urban Labor Market in China [J] .Sociological Study (2): 1-31.

[5] Zhang Chewei.2006.Human Capital Return and Income Disparity: Mathew Effect and Its Implication [J].Economic Research Journal(12):59-70.

[6] Zhang Yuan, Wang Hao.2011.Household Registration and Regional Discrimination on Urban Labor Market: Based on Census Data [J]Management World(7):42-51. 